\title{
Inquiry Based Learning as A Recommended Approach for Controversial Historical Issues Teaching. An Action Research with Pre-Service Teachers in Greece
}

\author{
Lampros Papadimas ${ }^{1}$ Alexandra Stavrianoudaki ${ }^{2}$ Antonis Smyrnaios $^{3}$ \\ University of Thessaly/ Department of Primary Education
}

\begin{abstract}
Inquiry-based learning (IBL) has been an effective method for increasing students' understanding of difficult historical topics like controversial historical issues (C.H.I.). The current action research aims to produce a theoretical educational framework/model that -based on IBL- could support pre-service teachers to be engaged in controversial issues activities and gradually feel confident enough to enhance these topics in their History lesson. The paradigm of "Occupation-Resistance-Civil War in Greece" (and specifically in Magnesia district) has been selected since it is considered as a highly controversial historic field. Fourteen pre-service teachers have been selected and involved in the study. Qualitative research methods, such as semi-structured interviews and participative observation, were used to capture the transformation of their beliefs and their perceived sufficiency to adopt IBL as a teaching method to teach C.H.I. The findings showed participants reformed historical habits of mind and their views about History Teaching. They also develop a wide repertoire of IBL activities and a deeper understanding of themselves in different facilitating roles/functions. The study concludes that this kind of pre-service teacher training can be a suitable method of boosting C.H.I. teaching and overcoming perceived obstacles to enhance them in the classroom. This research is co- financed by Greece and the European Union (European Social Fund- ESF) through the Operational Programme «Human Resources Development, Education and Lifelong Learning 2014-2020» in the context of the project "Inquiry Based Learning as a recommended approach for controversial historical issues teaching. Occupation, Resistance and Civil War in Magnesia. Action research with pre-service teachers of Department of Primary Education in the University of Thessaly" (MIS 5052288).
\end{abstract}

Keywords: Inquiry-based learning; Controversial Historical issues; Occupation; Resistance; Civil War. 